\title{
PROXIMAL FIBULAR OSTEOTOMY VERSUS MEDIAL OPENING WEDGE HIGH TIBIAL OSTEOTOMY TO TREAT MEDIAL COMPARTMENT KNEE OSTEOARTHRITIS: A RANDOMIZED CLINICAL TRIAL
}

\author{
Tarek Mohammed Khalil ${ }^{1}$, Wael Ahmed Mohammed Nassar ${ }^{1}$, Hossam Moussa Sakr \\ ${ }^{2}$, Zeiad Mohammed Zakaria ${ }^{1}$, Ashraf Mohammed El Seddawy ${ }^{1}$, Ahmed Mamdouh \\ Mokhtar Morsy ${ }^{3}$
}

${ }^{1}$ Orthopedic Surgery, ${ }^{2}$ Diagnostic Radiology Department, Faculty of Medicine, Ain Shams University,

${ }^{3}$ Saudi German Hospital, Cairo

Corresponding author

Ahmed Mamdouh Mokhtar Morsy

Mobile: (+2) 01225590108 E.mail: dr_ahmed_mumdouh@hotmail.com

Received: $9 / 2 / 2021$

Accepted: 3/3/2021

Online ISSN: 2735-3540

\begin{abstract}
:
Background: Osteoarthritis is the most common cause of disability in the older population. Disability is caused by pain and limitations in mobility. Total knee arthroplasty, which aims to relieve pain and improve joint function and mobility, is the main surgical alternative in this patient population.
\end{abstract}

Aim of the work: The aim of this work is to compare the functional and radiological outcomes of proximal fibular osteotomy in medial compartment decompression, with medial opening wedge high tibial osteotomy.

Patients and Methods: This prospective randomized clinical trial was done between March 2017 and May 2019 on 40 patients suffering from manifestation of medial compartment osteoarthritis of the knee joint. Patients were allocated into two groups: Control group; 20 patients representing the standard HTO technique and Case group; 20 patients representing the novel technique PFO.

Results: In our study we compared the outcome of 40 patient complaining of medial knee OA according to VAS, KSS and radiological assessment of joint space, we found improvement in outcome of HTO than PFO. However, PFO may be a promising alternative in most developing countries because of their financial and healthcare delivery limitations. Furthermore, these patients can still undergo TKA in the future if it becomes necessary, PFO may be considered in patients with mild medial compartment osteoarthritis over HTO.

Conclusion: Our preliminary data clearly demonstrate that PFO is a simple, fast and affordable surgery to relieve pain and improve joint function and the medial joint space in human knee osteoarthritis. However, in this study we only assessed the short term follow up, so further studies are needed to assess the long-term outcome.

Keywords: Proximal Fibular Osteotomy, Medial Opening Wedge, High Tibial Osteotomy, Treat Medial Compartment Knee Osteoarthritis

\section{INTRODUCTION:}

Osteoarthritis is the main cause of musculoskeletal disability in developing and developed countries in the elder population $^{(1)}$.

Knee osteoarthritis (OA) is a chronic, slowly progressive degenerative disease with 
accompanying joint pain, stiffness, and deformity. Disability is due to pain and limitation in the range of motion (ROM). ${ }^{(1)}$ Total Knee Replacement (TKR), is the main surgical intervention to relieve pain and improve ROM and function in patients with end stage disease. However, TKR is not the best option for younger patients as they may need second knee revision and there will be concerns about the longevity with more active patients in addition to the economic burden and complication of Arthroplasty. ${ }^{(2)}$

Although (HTO) is the first line of treatment in younger patients with medial compartment osteoarthritis of the knee, there are some potential complications after surgery. ${ }^{(3-6)}$

It was reported that proximal fibular osteotomy (PFO) improves function of the knee joint and effectively relieves the pain especially in medial compartment knee osteoarthritis. $^{(7)}$ The novel technique is relatively safe, simple and affordable, and may delay the need for TKR. ${ }^{(7,8)}$

In the present study, we will evaluate the short-term efficacy of PFO in comparison with HTO as regard radiological outcome, clinical and pain scores.

We will use a prospective Randomized clinical trial study design, to compare the outcome of the standard technique of medial opening wedge HTO for medial compartment decompression, with the novel technique of PFO.

\section{AIM OF THE WORK}

The aim of this work is to compare the functional and radiological outcomes of proximal fibular osteotomy (PFO) in medial compartment decompression, with medial opening wedge high tibial osteotomy (HTO), through a randomized clinical study (using the standard technique HTO as the control group to be compared with the novel technique; PFO as the case group).

\section{PATIENTS AND METHODS:}

This prospective randomized clinical trial was done between March 2017 and May 2019 on 40 patients suffering from manifestation of medial compartment osteoarthritis of the knee joint.

Patients were allocated into two groups: Control group; 20 patients representing the standard HTO technique and Case group; 20 patients representing the novel technique PFO. Subjects' allocation was randomized to avoid any bias.

Randomization of patients was done using computer generated randomization by Random Allocation Software into 2 groups: group A (patients treated by HTO) and group B (patients treated by PFO).

\section{Inclusion criteria:}

Patients were eligible for inclusion if they meet the following criteria:

- Middle age group (35-55) years with no difference to sex.

- Medial compartment knee osteoarthritis grade II, III (Kellgern \& Lawrence classification).

- Patients already exhausted conservative measures

- Varus deformity grade I-II (FemoroTibial angle $<20^{\circ}$ ).

\section{Exclusion criteria:}

- Elder age group (> 55 years old).

- Severe knee osteoarthritis grade IV (Kellgern \& Lawrence classification).

- Patient underwent any surgical intervention on the knee in the previous 6 months (e.g. arthroscopic debridement).

- Severe varus deformity (Femoro-Tibial angle $>20$ ).

- Inflammatory joint disease e.g. Rheumatoid arthritis 
- Dynamic instability or ligamentous Insufficiency.

- Post traumatic osteoarthritis.

The scoring systems we had chosen to assess pain and function of knee are:

1. Visual Analogue scale of pain (VAS). ${ }^{(9)}$

2. Knee Society Score (KSS). ${ }^{(10)}$

3. Radiological assessment of medial joint space of knee by $\mathrm{mm} .{ }^{(12)}$

\section{Statistical Analysis}

Data were collected, revised, coded and entered to the Statistical Package for Social Science (IBM SPSS) version 23. The quantitative data were presented as mean, standard deviations and ranges when their distribution found parametric and median with inter-quartile range (IQR) when their distribution found non parametric. Also qualitative variables were presented as number and percentages. The $\mathrm{p}$-value was considered significant as the following: $\mathrm{P}>$ 0.05: Non significant, $\mathrm{P}<0.05$ : Significant, $\mathrm{P}<0.01$ : Highly significant.
Medial opening wedge High Tibial Osteotomy:

\section{Surgical technique:}

After preoperative evaluation and preparation of the patients, the operation was done according to the following steps under general or spinal anesthesia: -

Step 1: Patient position

Step 2: Incision and Exposure

Step 3: Osteotomy

Step 4: Plate Fixation

Postoperative rehabilitation

Proximal Fibular Osteotomy:

\section{Surgical technique}

Step 1: patient position

Step 2: Incision and Exposure

\section{Postoperative rehabilitation}

Full weight bearing and free mobilization were allowed postoperatively. Postoperative standing x-ray done.

\section{RESULTS:}

Table 1: Age, sex and side affected among the studied patients

\begin{tabular}{|c|c|c|}
\hline \multirow{2}{*}{ Age } & Mean \pm SD & No.=40 \\
\cline { 2 - 3 } & Range & $35-05 \pm 6.35$ \\
\hline \multirow{2}{*}{ Sex } & Females & $17(42.5 \%)$ \\
\cline { 2 - 3 } & Males & $23(57.5 \%)$ \\
\hline \multirow{2}{*}{ Side } & Right & $19(47.5 \%)$ \\
\cline { 2 - 3 } & Left & $21(52.5 \%)$ \\
\hline
\end{tabular}

Table 2: Comparison between the two studied groups regarding age, sex and side affected

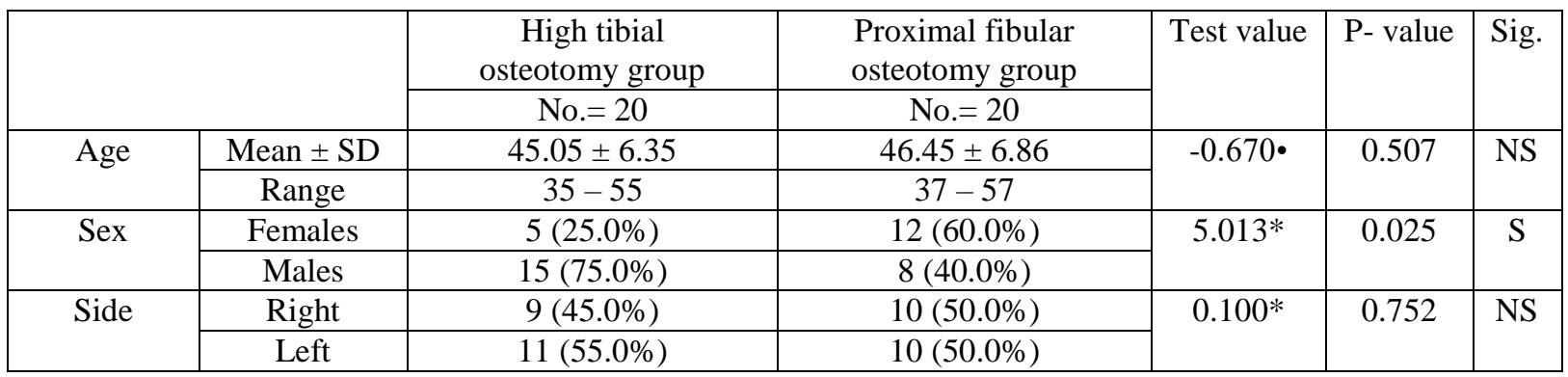

P-value >0.05: Non significant (NS); P-value <0.05: Significant (S); P-value< 0.01: highly significant (HS) *:Chi-square test; $\bullet$ : Independent t-test. 
The previous table shows that there was no statistically significant difference found between the two studied groups regarding age and side affected of the studied patients with $\mathrm{p}$-value $=0.507$ and 0.752 respectively while there was statistically significant difference found between them regarding sex distribution with $\mathrm{p}$-value $=0.025$.

Table 3: Comparison between the two studied groups regarding preoperative parameters

\begin{tabular}{|c|c|c|c|c|c|c|}
\hline \multicolumn{2}{|c|}{ Preoperative } & High tibial & Proximal fibular & \multirow{2}{*}{$\begin{array}{c}\text { Test } \\
\text { value } \neq\end{array}$} & \multirow[t]{2}{*}{ P-value } & \multirow[t]{2}{*}{ Sig. } \\
\hline & & No. $=20$ & No. $=20$ & & & \\
\hline \multirow[t]{3}{*}{ VAS } & Mean \pm SD & $7.95 \pm 0.83$ & $8.20 \pm 0.77$ & \multirow[t]{3}{*}{-0.978} & \multirow[t]{3}{*}{0.328} & \multirow[t]{3}{*}{ NS } \\
\hline & Median (IQR) & $8(7-9)$ & $8(8-9)$ & & & \\
\hline & Range & $7-9$ & $7-9$ & & & \\
\hline \multirow[t]{3}{*}{ KSS } & Mean \pm SD & $57.80 \pm 4.62$ & $58.05 \pm 5.27$ & \multirow[t]{3}{*}{-0.095} & \multirow[t]{3}{*}{0.924} & \multirow[t]{3}{*}{$\mathrm{NS}$} \\
\hline & Median (IQR) & $57(53.5-62)$ & $57.5(53.5-61)$ & & & \\
\hline & Range & $51-65$ & $52-72$ & & & \\
\hline \multirow[t]{3}{*}{ Radio } & Mean \pm SD & $2.45 \pm 0.67$ & $2.69 \pm 0.73$ & \multirow[t]{3}{*}{-1.330} & \multirow[t]{3}{*}{0.184} & \multirow[t]{3}{*}{ NS } \\
\hline & Median (IQR) & $2.55(2.05-2.9)$ & $2.95(1.8-3.1)$ & & & \\
\hline & Range & $1.2-3.5$ & $1.6-3.7$ & & & \\
\hline
\end{tabular}

P-value >0.05: Non significant (NS); P-value <0.05: Significant (S); P-value < 0.01: highly significant (HS) $\neq$ : Mann Whitney test

The previous table shows that there was no statistically significant difference found preoperative VAS, KSS and radio with pbetween the two studied groups regarding value $=0.328,0.924$ and 0.184 respectively.

Table 4: Comparison between the two studied groups regarding postoperative parameters

\begin{tabular}{|c|c|c|c|c|c|c|}
\hline \multicolumn{2}{|c|}{ Postoperative } & High tibial & Proximal fibular & \multirow{2}{*}{$\begin{array}{c}\text { Test } \\
\text { value } \neq\end{array}$} & \multirow[t]{2}{*}{ P-value } & \multirow[t]{2}{*}{ Sig } \\
\hline & & No. $=20$ & No. $=20$ & & & \\
\hline \multirow[t]{3}{*}{ VAS } & Mean \pm SD & $4.15 \pm 1.09$ & $3.25 \pm 1.89$ & \multirow[t]{3}{*}{-2.559} & \multirow[t]{3}{*}{0.011} & \multirow[t]{3}{*}{ S } \\
\hline & Median (IQR) & $4(3-5)$ & $3(2-3.5)$ & & & \\
\hline & Range & $3-6$ & $1-8$ & & & \\
\hline \multirow[t]{3}{*}{ KSS } & Mean \pm SD & $85.20 \pm 4.71$ & $83.65 \pm 9.64$ & \multirow[t]{3}{*}{-0.340} & \multirow[t]{3}{*}{0.734} & \multirow[t]{3}{*}{$\mathrm{NS}$} \\
\hline & Median (IQR) & $87(82-89)$ & $87(82.5-90)$ & & & \\
\hline & Range & $75-91$ & $60-93$ & & & \\
\hline \multirow[t]{3}{*}{ Radio } & Mean \pm SD & $3.25 \pm 0.66$ & $3.60 \pm 0.86$ & \multirow[t]{3}{*}{-2.100} & \multirow[t]{3}{*}{0.036} & \multirow[t]{3}{*}{$\mathrm{S}$} \\
\hline & Median (IQR) & $3.4(3.1-3.75)$ & $3.9(2.8-4.11)$ & & & \\
\hline & Range & $1.9-4.1$ & $2-4.7$ & & & \\
\hline
\end{tabular}

P-value $>0.05$ : Non significant (NS); P-value <0.05: Significant (S); P-value $<0.01$ : highly significant (HS) $\neq$ : Mann Whitney test

The previous table shows that there was no statistically significant difference found between the two studied groups regarding postoperative KSS score with $\mathrm{p}$-value = 0.734 while there was statistically significant increase in VAS score in high tibial

osteotomy group than proximal fibular osteotomy group with $\mathrm{p}$-value $=0.011$ and also statistically significant increase in radio in proximal fibular osteotomy group than high tibial osteotomy group with $\mathrm{p}$-value $=$ 0.036 . 
Table 5: Comparison between preoperative and postoperative parameters in the high tibial osteotomy group

\begin{tabular}{|c|c|c|c|c|c|c|}
\hline & Preoperative & Postoperative & \multirow[t]{2}{*}{ Test value } & \multirow[t]{2}{*}{ P-value } & \multirow[t]{2}{*}{ Sig. } \\
\hline & & No. $=20$ & No. $=20$ & & & \\
\hline \multirow[t]{3}{*}{ VAS } & Mean \pm SD & $7.95 \pm 0.83$ & $4.15 \pm 1.09$ & \multirow[t]{3}{*}{$-3.955 \neq$} & \multirow[t]{3}{*}{0.000} & \multirow[t]{3}{*}{ HS } \\
\hline & Median (IQR) & $8(7-9)$ & $4(3-5)$ & & & \\
\hline & Range & $7-9$ & $3-6$ & & & \\
\hline \multirow[t]{3}{*}{ KSS } & Mean \pm SD & $57.8 \pm 4.62$ & $85.2 \pm 4.71$ & \multirow[t]{3}{*}{$-3.923 \neq$} & \multirow[t]{3}{*}{0.000} & \multirow[t]{3}{*}{ HS } \\
\hline & Median (IQR) & $57(53.5-62)$ & $87(82-89)$ & & & \\
\hline & Range & $51-65$ & $75-91$ & & & \\
\hline \multirow[t]{3}{*}{ Radio } & Mean \pm SD & $2.45 \pm 0.67$ & $3.25 \pm 0.66$ & \multirow[t]{3}{*}{$-9.189 \bullet$} & \multirow[t]{3}{*}{0.000} & \multirow[t]{3}{*}{ HS } \\
\hline & Median (IQR) & $2.55(2.05-2.9)$ & $3.4(3.1-3.75)$ & & & \\
\hline & Range & $1.2-3.5$ & $1.9-4.1$ & & & \\
\hline
\end{tabular}

P-value >0.05: Non significant (NS); P-value <0.05: Significant (S); P-value $<0.01$ : highly significant (HS) $\neq$ : Wilcoxon Rank test $\bullet$ : Paired t- test

The previous table shows that there was statistically significant decrease in VAS and increase in KSS and radio in high tibial

osteotomy group postoperative than preoperative with $\mathrm{p}$-value $<0.001,<0.001$ and $<0.001$ respectively.

Table 6: Comparison between preoperative and postoperative parameters in the proximal fibular osteotomy group

\begin{tabular}{|c|c|c|c|c|c|c|}
\hline & Preoperative & Postoperative & \multirow[t]{2}{*}{ Test value• } & \multirow[t]{2}{*}{ P-value } & \multirow[t]{2}{*}{ Sig. } \\
\hline & & No. $=20$ & No. $=20$ & & & \\
\hline \multirow[t]{3}{*}{ VAS } & Mean \pm SD & $8.20 \pm 0.77$ & $3.25 \pm 1.89$ & \multirow[t]{3}{*}{$-3.953 \neq$} & \multirow[t]{3}{*}{0.000} & \multirow[t]{3}{*}{ HS } \\
\hline & Median (IQR) & $8(8-9)$ & $3(2-3.5)$ & & & \\
\hline & Range & $7-9$ & $1-8$ & & & \\
\hline \multirow[t]{3}{*}{ KSS } & Mean \pm SD & $58.05 \pm 5.27$ & $83.65 \pm 9.64$ & \multirow[t]{3}{*}{$-3.936 \neq$} & \multirow[t]{3}{*}{0.000} & \multirow[t]{3}{*}{$\mathrm{HS}$} \\
\hline & Median (IQR) & $57.5(53.5-61)$ & $87(82.5-90)$ & & & \\
\hline & Range & $52-72$ & $60-93$ & & & \\
\hline \multirow[t]{3}{*}{ Radio } & Mean \pm SD & $2.69 \pm 0.73$ & $3.60 \pm 0.86$ & \multirow[t]{3}{*}{$-16.627 \bullet$} & \multirow[t]{3}{*}{0.000} & \multirow[t]{3}{*}{ HS } \\
\hline & Median (IQR) & $2.95(1.8-3.1)$ & $3.9(2.8-4.11)$ & & & \\
\hline & Range & $1.6-3.7$ & $2-4.7$ & & & \\
\hline
\end{tabular}

P-value >0.05: Non significant (NS); P-value <0.05: Significant (S); P-value< 0.01: highly significant $(\mathrm{HS}) \neq$ : Wilcoxon Rank test $\bullet$ : Paired t- test

The previous table shows that there was statistically significant decrease in VAS and increase in KSS and radio in proximal

fibular osteotomy group postoperative than preoperative with $\mathrm{p}$-value $<0.001,<0.001$ and $<0.001$ respectively.

Table 7: Comparison between the two studied groups regarding change between pre and postoperative

\begin{tabular}{|c|c|c|c|c|c|c|}
\hline \multicolumn{2}{|c|}{ Differences } & High tibial & Proximal fibular & \multirow{2}{*}{$\begin{array}{c}\text { Test } \\
\text { value } \neq\end{array}$} & \multirow[t]{2}{*}{$\mathrm{P}$ - value } & \multirow[t]{2}{*}{ Sig. } \\
\hline & & No. $=20$ & No. $=20$ & & & \\
\hline \multirow[t]{3}{*}{ VAS reduction } & Mean \pm SD & $3.80 \pm 1.28$ & $4.95 \pm 1.85$ & \multirow[t]{3}{*}{-2.441} & \multirow[t]{3}{*}{0.015} & \multirow[t]{3}{*}{$\mathrm{S}$} \\
\hline & Median (IQR) & $4(3-4.5)$ & $5(4.5-6)$ & & & \\
\hline & Range & $1-6$ & $1-8$ & & & \\
\hline \multirow[t]{3}{*}{ KSS elevation } & Mean \pm SD & $27.40 \pm 7.13$ & $25.60 \pm 8.17$ & \multirow[t]{3}{*}{-0.463} & \multirow[t]{3}{*}{0.643} & \multirow[t]{3}{*}{ NS } \\
\hline & Median (IQR) & $28(23-31.5)$ & $29(24-31)$ & & & \\
\hline & Range & $10-39$ & $7-35$ & & & \\
\hline \multirow[t]{3}{*}{ Radio elevation } & Mean \pm SD & $0.80 \pm 0.39$ & $0.92 \pm 0.25$ & \multirow[t]{3}{*}{-1.334} & \multirow[t]{3}{*}{0.182} & \multirow[t]{3}{*}{ NS } \\
\hline & Median (IQR) & $0.75(0.45-1.1)$ & $1(0.9-1.1)$ & & & \\
\hline & Range & $0.3-1.7$ & $0.4-1.2$ & & & \\
\hline
\end{tabular}

P-value >0.05: Non significant (NS); P-value <0.05: Significant (S); P-value < 0.01: highly significant (HS) $\neq$ : Mann Whitney test 
The previous table shows that there was statistically significant increase in the reduction rate of VAS score in proximal fibular osteotomy group than high tibial osteotomy group with $\mathrm{p}$-value $=0.015$ while no statistically significant difference found between them regarding the change in KSS and radio with $\mathrm{p}$-value $=0.643$ and 0.182 respectively.

\section{Complications of HTO:}

In this study a Deep vein thrombosis was detected in one patient treated satisfactorily with medical therapy and leg elevation. One patient needed iliac bone grafting because of wedge size $(22 \mathrm{~mm})$ and above knee slab for 6 weeks. Moreover, we delayed the weight bearing for 6 to 11 weeks which displeased few patients.

\section{Complications of PFO:}

In this study there was no skin wound infections. Four cases complained of inability to elevate big toe (extensor hallux longus neuropraxia) which was observed 6 month after surgery and improved with neurotonic medications, Weight bearing start immediately after operation. Additionally, two cases showed symptoms of deep Peroneal nerve affection (tingling, numbness and neuropathic pain along first dorsal web space) which did not respond to neurotonics. One case complained of recurrence of knee pain and underwent HTO and improved afterwards.

Table 8: Complications among the high tibial osteotomy group

\begin{tabular}{|c|c|}
\hline Complications & High tibial osteotomy group \\
\cline { 2 - 2 } & No. (\%) \\
\hline DVT & $1(5.0 \%)$ \\
\hline Bone grafting & $1(5.0 \%)$ \\
\hline
\end{tabular}

Table 9: Complications among the proximal fibular osteotomy group

\begin{tabular}{|c|c|}
\hline Complications & Proximal fibular osteotomy group \\
\cline { 2 - 2 } & No. $(\%)$ \\
\hline Extensor hallux longus neuropraxia & $4(20.0 \%)$ \\
\hline Deep Peroneal nerve affection & $2(10.0 \%)$ \\
\hline Recurrence of knee pain & $2(10.0 \%)$ \\
\hline Severe intraoperative bleeding & $1(5.0 \%)$ \\
\hline
\end{tabular}

\section{DISCUSSION:}

Osteotomy offers an alternative surgical option to total knee replacement in reducing pain and improving function especially in younger and more physically active people with Osteoarthritis of the knee ${ }^{(\mathbf{1 3})}$.

Considering two type of osteotomy HTO and PFO are the best option in treatment of early stages of medial compartment of OA knee.

Regarding the selection of which type of osteotomy, we found that; since the reports of Hernigou et al. ${ }^{(11)}$ on open-wedge medial osteotomy published in 1951, both the technique and the implants used have undergone considerable modifications. In medial open-wedge osteotomy, fibular osteotomy is not performed, technique does not require a wide exposure and a stable fixation can be accomplished with a Puddu plate without loss of correction.

Medial opening wedge HTOs have become increasingly popular over the past 2 decades. The procedure is attractive because the peroneal nerve is not in jeopardy and disruption of the proximal tibiofibular joint and lateral ligaments is avoided ${ }^{(\mathbf{1 4})}$. 
Hernigou et al. ${ }^{(11)}$ followed 93 cases with arthrosis of the medial compartment that had undergone open-wedge osteotomies for a median of 11.5 years, and reported that the results obtained were satisfactory up to 7 years postoperatively. Magyar et al. practiced medial open-wedge osteotomy (25 knees) or close wedge osteotomy (25 knees) for 50 knees of 46 patients, and reported that after 2 years of follow-up, clinical scores had improved in both groups without a significant difference between groups. ${ }^{(14)}$

Success in medial open-wedge osteotomy depends largely on sound application of the technique. The determination of the exact localization of the osteotomy site accurately under a good fluoroscopic control, meticulous care not to fracture lateral cortex during opening of the osteotomy site, frequent assessment of the correction angle at every step of the operation, avoidance of overcorrection, the selection of an appropriate Puddu plate size fit for the osteotomy gap are important details increasing the success rate of this procedure. $^{(16)}$

In our study based on follow-up of the patients, mean improvements obtained in KSS scores was $85.40 \pm 5.62$. According to this assessment scale, preoperative score was deemed "worse", and postoperative scores was "'good' 'table (10)

Table 10: Comparison between preoperative and postoperative assessment in high tibial osteotomy

\begin{tabular}{|c|c|c|c|c|c|c|}
\hline \multicolumn{2}{|c|}{$\begin{array}{l}\text { High tibial } \\
\text { osteotomy }\end{array}$} & $\begin{array}{c}\text { Preoperative } \\
\text { assessment }\end{array}$ & $\begin{array}{c}\text { Postoperative } \\
\text { assessment }\end{array}$ & Test value* & P-value & Sig. \\
\hline \multirow[t]{2}{*}{ VAS } & Mean \pm SD & $7.80 \pm 0.79$ & $4.20 \pm 1.14$ & \multirow[t]{2}{*}{7.962} & \multirow[t]{2}{*}{$<0.001$} & \multirow[t]{2}{*}{$\mathrm{HS}$} \\
\hline & Range & $7-9$ & $3-6$ & & & \\
\hline \multirow[t]{2}{*}{ KSS } & Mean \pm SD & $58.70 \pm 4.74$ & $85.40 \pm 5.62$ & \multirow[t]{2}{*}{10.499} & \multirow[t]{2}{*}{$<0.001$} & \multirow[t]{2}{*}{ HS } \\
\hline & Range & $52-65$ & $75-91$ & & & \\
\hline \multirow[t]{2}{*}{ Radio } & Mean \pm SD & $2.59 \pm 0.68$ & $3.35 \pm 0.67$ & \multirow[t]{2}{*}{6.413} & \multirow[t]{2}{*}{$<0.001$} & \multirow[t]{2}{*}{$\mathrm{HS}$} \\
\hline & Range & $1.2-3.5$ & $1.9-4.1$ & & & \\
\hline
\end{tabular}

*: Paired t-test

In addition, the radiological examinations revealed that the mechanical axes on the average passed $5.09 \mathrm{~mm}$ laterally achieving an average of 5 genu valgum

Early outcomes of the medial openwedge osteotomies with Puddu plates are successful and safe; however, PFO is considered a better option for treatment of early stage of medial OA of knee with early weight bearing.

HTO has been the surgical treatment of choice for young patients with osteoarthritis of the medial compartment of the knee, and it is aimed at correcting alignment and delaying the time until TKA is required ${ }^{(\mathbf{1 5})}$. However, HTO also has some disadvantages, including a delayed time to full weight bearing and risks of nonunion or delayed union as well as wound infection $^{(16,17)}$.
PFO has emerged as a new surgery to relieve pain and improve joint function in patients with knee osteoarthritis as reported by Zhang et $\boldsymbol{a l}^{(\mathbf{2})}$. The most significant results in his study included medial pain relief and an increase in the medial joint space.

Zhang et al. followed 46 patients for a minimum of 12 months. The mean duration of follow-up was 13.38 months (range, 1218 months). The average duration of unilateral PFO was $32.23 \pm 9.13$ minutes. No postoperative complications were observed, including wound infection, delayed healing or nerve damage. Notably, medial pain relief was observed in all patients after PFO. The mean visual analogue scale scores significantly decreased from $8.02 \pm 1.50$ preoperatively to $2.74 \pm 2.34$ postoperatively. Preoperatively, the mean knee and function sub scores of the American Knee Society 
score were $44.41 \pm 8.90$ and $41.24 \pm 13.48$, respectively. Postoperatively, they significantly improved to $69.02 \pm 11.12$ and $67.63 \pm 13.65$. Radiographs of the weightbearing lower extremity showed an average increase in the medial knee joint space postoperatively compared with preoperatively. The ratio of the knee joint space (medial/lateral compartment) improved significantly from $0.40 \pm 0.28$ preoperatively

Table 11: Comparison between preoperative and postoperative assessment in high fibular osteotomy.

\begin{tabular}{|c|c|c|c|c|c|c|}
\hline \multicolumn{2}{|c|}{$\begin{array}{c}\text { High fibular } \\
\text { osteotomy }\end{array}$} & $\begin{array}{c}\text { Preoperative } \\
\text { assessment }\end{array}$ & $\begin{array}{c}\text { Postoperative } \\
\text { assessment }\end{array}$ & Test value* & P-value & Sig \\
\hline \multirow[t]{2}{*}{ VAS } & Mean \pm SD & $8.00 \pm 0.67$ & $3.00 \pm 0.94$ & \multirow[t]{2}{*}{16.771} & \multirow[t]{2}{*}{$<0.001$} & \multirow[t]{2}{*}{ HS } \\
\hline & Range & $7-9$ & $2-5$ & & & \\
\hline \multirow[t]{2}{*}{ KSS } & Mean \pm SD & $56.60 \pm 3.98$ & $91.00 \pm 4.16$ & \multirow[t]{2}{*}{17.534} & \multirow[t]{2}{*}{$<0.001$} & \multirow[t]{2}{*}{ HS } \\
\hline & Range & $52-65$ & $81-95$ & & & \\
\hline \multirow[t]{2}{*}{ Radio } & Mean \pm SD & $2.78 \pm 0.67$ & $3.80 \pm 0.59$ & \multirow[t]{2}{*}{22.881} & \multirow[t]{2}{*}{$<0.001$} & \multirow[t]{2}{*}{ HS } \\
\hline & Range & $1.6-3.7$ & $2.8-4.7$ & & & \\
\hline
\end{tabular}

Although the pain decreased in most of the patients; however, two patients continued to complain one underwent HTO and the other had a TKR. Postoperative ambulation (i.e. walking) was also obviously improved when compared with the preoperative state. PFO also improved the axial alignment of the lower extremity in some patients, especially in those with genu varum.

Compared with TKA or HTO, PFO is a simple, safe, fast and affordable surgery that does not require insertion of additional implants. As such, PFO is a suitable surgical option in most developing countries that lack financial and medical resources.

This novel surgery may potentially become an alternative treatment method for osteoarthritis of the medial compartment of the knee, especially for patients with low tibio-femoral angles who cannot undergo TKA because of medical comorbidities. However, several limitations to this study must be noted. First, although the short-term results are encouraging, the follow-up time was relatively short, and whether these outcomes will remain unchanged at a longer follow-up time is unclear. Therefore, a longer follow-up study is warranted. In to $0.58 \pm 0.30$ postoperatively. Additionally, an obvious correction of alignment in the observed in 8 out of 46 patients. ${ }^{\text {(2) }}$

In our study most of the patients had significant pain relief immediately after PFO. Additionally, there are improvement in the VAS, KSS and radiological assessment of medial joint space Table (11). whole-lower-extremity radiographs was

addition, the mechanism of the efficacy of PFO is unclear. One possible explanation of why PFO relieves pain and improves the joint space is that it removes the fibula support that may cause genu varum. The fibula supports one-sixth of the body weight; thus, PFO may rebalance or redistribute the load on the lateral and medial tibia plateau after surgery ${ }^{(\mathbf{1 8})}$. Knee OA could also be called a "stress imbalanced syndrome of the knee joint". PFO weakens the lateral fibular support and leads to a correction of the varus deformity, which can subsequently shift the loading force from the medial compartment more laterally, leading to decreased pain and a satisfactory functional recovery. ${ }^{(8)}$

Another possible mechanism is no uniform settlement as proposed by Yang et

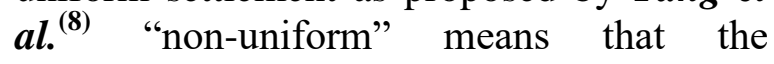
settlement of the plateau is asymmetric, with settlement in the medial plateau more obvious than in the lateral plateau. Moreover, they stated that the lateral support provided to the osteoporotic tibia by the fibula-soft tissue complex may lead to no uniform settlement and degeneration of the plateau bilaterally, which may cause the load from the normal distribution to shift farther medially to the medial plateau, consequently 
leading to knee varus deformity and aggravating the progression of medial compartment osteoarthritis of the knee joint. Because only six patients in our study exhibited obvious correction of alignment, the reason for this phenomenon remains unclear. Furthermore, the long-term side effects of PFO on other joints of the lower extremity, such as the hip and ankle, remain unknown as well as the biomechanics of pain relief, increases in the medial joint space, and correction of alignment in patients who have undergone the procedure $^{(19)}$

In our study we compared the outcome of 40 patient complaining of medial knee OA according to VAS, KSS and radiological assessment of joint space, we found improvement in outcome of HTO than PFO. However, PFO may be a promising alternative in most developing countries because of their financial and healthcare delivery limitations. Furthermore, these patients can still undergo TKA in the future if it becomes necessary.

\section{REFERENCES}

1. Focht BC. Move to improve: how knee osteoarthritis patients can use exercise to enhance quality of life. ACSM's Health Fit J. 2012; 16:24-28.

2. Zhang YZ. Innovations in Orthopedics and Traumatology in China. Chin Med J (Engl) 2015; 128:2841-2842.

3. Vincent KR, Conrad BP, Fregly BJ, et al. The pathophysiology of osteoarthritis: a mechanical perspective on the knee joint. PM\&R. 2012; 4(5):S3-S9.

4. Shiozaki H, Koga Y, Omori G, et al. Epidemiology of osteoarthritis of the knee in a rural Japanese population. Knee. 1999; 6(3):183-188.
5. Petersson IF, Boegård T, Saxne T, et al. Radiographic Osteoarthritis of the knee classified by the Ahlbäck and Kellgern \& Lawrence systems for the tibiofemoral joint in people aged 35-54 years with chronic knee pain, Annals of the Rheumatic Disease 1997; 56:493-476.

6. Wu LD, Hahne HJ, Hassenpflug T. A longterm follow-up study of high tibial osteotomy for medial compartment osteoarthrosis. Chin J Traumatol. 2004; 7:348-353.

7. Wang $\mathrm{X}$, Wei $\mathrm{L}, \mathrm{Lv} \mathrm{Z}$, et al. Medial Proximal Fibular Osteotomy: a new surgery for pain relief amd improvement of joint functionin patients with knee osteoarthritis. Journal of international medical research 2017; 45(1): 282-289.

8. Yang ZY, Chen W, Li CX, et al. Medial Compartment Decompression by Fibular Osteotomy to Treat Medial Compartment Knee Osteoarthritis; A Pilot Study. 2015; 38(12):e1110-e1114.

9. Felson D. The sources of pain in knee osteoarthritis. Curr Opin Rheumatol 2005; 17:624-8.

10. Chesnut WJ. Preoperative diagnostic protocol to predict candidates for unicompartmental arthroplasty. Clin Orthop, 1991; 273: 146-150.

11. Davide Edorado Bonasia, Giorgio Governate, Simone Spolore et al. High tibial osteotomy, Modern Techniques in lower limb realignment, Current Reviews in Musculoskeletal Medicine 2014 7; 292-301.

12. Hunter DJ, Buck R, Vignon $\mathrm{E}$, et al. Relation of regional articular cartilage morphometry and meniscal position by MRI to joint space width in knee radiographs. Osteoarthritis Cartilage. 2009; 17(9):1170-1176.

13. Giuseppe M. Joint Preservation of Knee: What Is Its Value?. Joints 2017; 5:57-58.

14. Spahn G. Complications in high tibial (medial opening wedge) osteotomy. Arch Orthop Trauma Surg. 2004; 124:649-653. 
15. Duivenvoorden T, Brouwer RW, Baan A, et al. Comparison of closing-wedge and opening-wedge high tibialosteotomy for medial compartment osteoarthritis of the knee: a randomized controlled trial with a sixyear follow-up. J Bone Joint Surg Am 2014; 96: 1425-1432.

16. Sprenger TR and Doerzbacher JF. Tibial osteotomy for the treatment of varus gonarthrosis. Survival and failure analysis to twenty-two years. J Bone Joint Surg Am 2003; 85-A: 469-474.

17. Dahl A, Robertsson $\mathrm{O}$ and Lidgren V. Surgery for knee osteoarthritis in younger patients. Acta Orthop 2010; 81: 161-164.
18. Wei XC, Wang XH, Li PC, et al. Proximal fibular osteotomy, a new surgery for pain relief and improvement of joint function in human knee osteoarthritis: a short-term clinical study. poster \#: 1071. ORS 2016 Annual meeting at the Disney's Coronado springs resort in Orlando, Florida, March 58.

19. Dong T, Chen W, Zhang F, et al. Radiographic measures of settlement phenomenon in patients with medial compartment knee osteoarthritis. Clin Rheumatol. 2016; 35(6):1573- 1578.

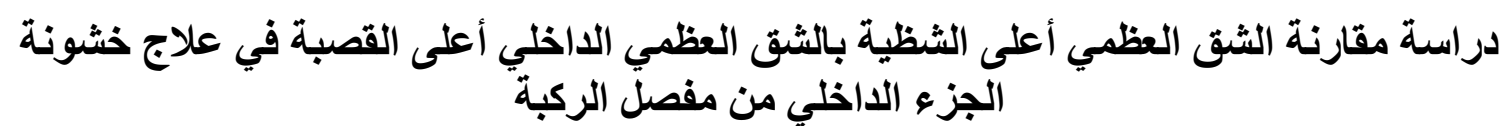

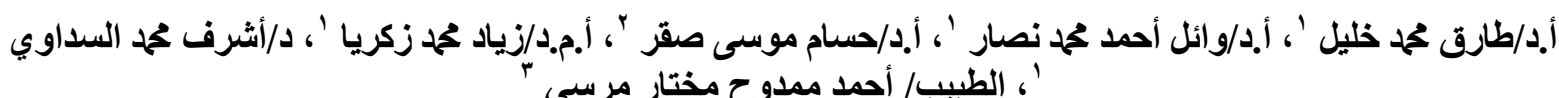

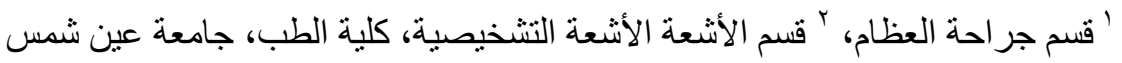$$
\text { "مستشفي السعودي الالماني }
$$

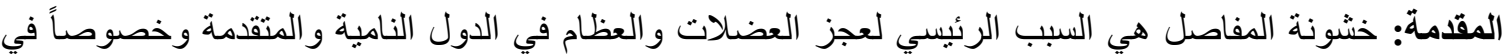

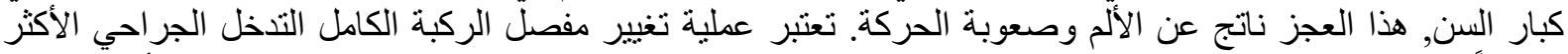

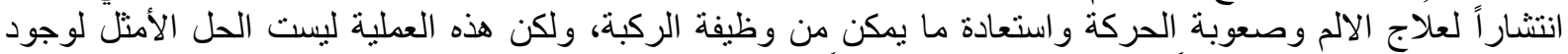

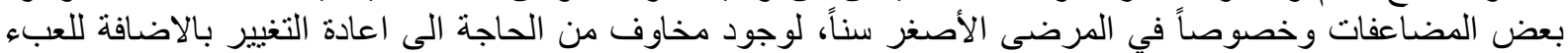
الاقتصادي لها.

الهيف من الدراسة: هو المقارنة بين النتائج الاكلينيكية ونتائج البحث الاشعاعي لعملية الثق أعلى عظمة الثظية

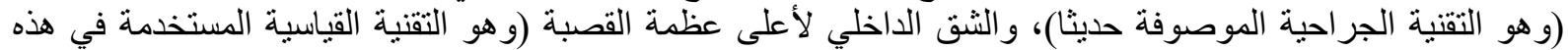
الحالات). من خلال در اسة للحالات و النشو اهد.

المرضي وطرق البحث: بعد عمل الدراسه علي عدد عشرون حالة عن طريق شق عظمي اعلي عظمه القصبه و عشرون حالّة اخري بشنق عظمي البحن بعدي عظمه الثظيه.

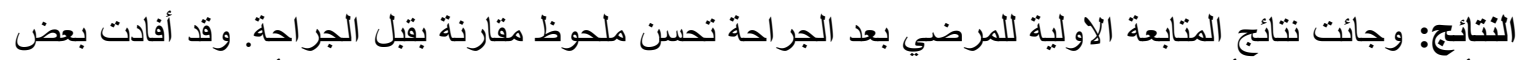
الأبحاث أن الثق العظمي أعلي عظمة الثظية قد يساعد في تحسين وظيفة مفصل الركبة ويعالج الألم الناتج عنده، بتقنية سهلة وبسيطة وامنة بدون تكلفة المفصل الصناعية.

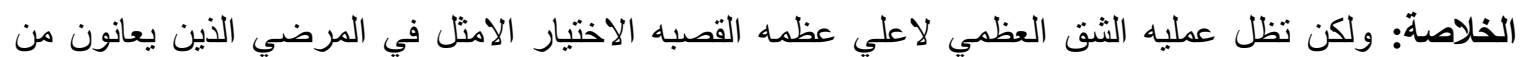
خشونه في الجزء الداخلي للركبه مصاحباً لاعوجاج داخلي شئي لاعديد للركبه. 